\title{
Türk Bankacılık Sektöründe Aktif Büyüklüğü ile Risk Alma Davranışı Arasındaki İlişkinin Analizi
}

\section{Analysis of The Relationship Between Asset Size and Risk Taking Behavior in the Turkish Banking Sector}

\author{
Serdar Kuzu a,*, Gülşah Gençer Çelik ${ }^{\text {b }}$ \\ ${ }^{a}$ Doç.Dr., İstanbul Üniversitesi Cerrahpaşa, Sosyal Bilimler Meslek Yüksekokulu, Muhasebe ve Vergi Bölümü, İstanbul/Türkiye. \\ ORCID: 0000-0001-8178-8749*

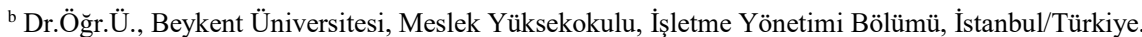 \\ ORCID: 0000-0001-8610-3673
}

\section{MAKALE BİLGİSİ}

\section{Makale Geçmişi:}

Başvuru tarihi: 30 Eylül 2020

Düzeltme tarihi: 04 Kasım 2020

Kabul tarihi: 11 Kasım 2020

\section{Anahtar Kelimeler:}

Türk Bankacilık Sektörü

Risk Alma Davranışı

Johansen Eşbütünleşme

Batamayacak Kadar Büyük
ÖZ

Temel işlevleri çerçevesinde bankacılık bir risk alma ve yönetme işi olduğundan, bankacılık faaliyetlerinden kaynaklanan risklerin gereğince anlaşılması, ölçülmesi ve iyi yönetilmesi gereklidir. Finansal sektörün temel yapı taşını oluşturan bankalar, finansal istikrarın sağlanmasında önemli rol oynamaktadırlar. Özellikle bankaların yüksek kar sağlayabilmek bağlamında, daha riskli davranışlarda bulunması finansal düzene yönelik tehdit oluşturabilmektedir. Bu açıdan ele alındığında bankaların risk alma davranışları üzerinde etkili olabilecek unsurların tespit edilebilmesi, finansal istikrar açısından büyük önem arz etmektedir.

Bankacılık sektörüne yönelik olarak yapılan sektör düzenlemeleri, makroekonomik düzenlemeler, bankaların sermaye yapıları, büyüklügü̈, kredi hacmi, aktif büyüklüğü ve finansman yapısı gibi değişkenler bankaların risk alma davranışları üzerinde etkili olmaktadır. Bu çalışmanın amacı Türk bankacılık sektöründe risk alma davranışı ve bu davranışa etki edebilecek faktörlerin etkilerinin tespit edilebilmesidir.

\section{A B S T R AC T}

Since banking is a risk taking and management business within its core functions, it is necessary to properly understand, measure and manage the risks arising from banking activities. Banks, which are the basic building blocks of the financial sector, play an important role in ensuring financial stability. Especially in the context of high profits, banks behaving riskier can pose a threat to the financial order. In this respect, it is of great importance in terms of financial stability to identify the factors that may have an impact on banks' risk-taking behavior. Variables such as sector regulations made for the banking sector, macroeconomic regulations, banks 'capital structures, size, loan volume, asset size and financing structure affect banks' risk-taking behavior. The purpose of this study is to determine the risk taking behavior in the Turkish banking sector and the effects of the factors that may affect this behavior.
Keywords:

Turkish Banking Sector

Risk Taking Behavior

Johansen Cointegration

Too big to fail boyutlarını göstermesi açısından, son derece dikkat çekici olmuştur. Bu nedenle bankaların sermaye yapıları ve çeşitli makroekonomik göstergeler karşısında risk alma davranışları büyük önem arz etmektedir. Her bankanın risk alma davranış felsefesi farklı olup; bu farklılık bankaların strateji ve hedeflerini etkilemektedir. Risk alma isteği daha

* Sorumlu yazar/Corresponding author.

e-posta: serdar.kuzu@ @istanbul.edu.tr 
fazla olan bankalar, sermayesinin büyük bir kısmını daha riskli alanlara yani gelişmekte olan piyasalara yatırabilmektedir. Dünyada yaşanan finansal krizlerin yer açtığg kayıpların en önemli nedenlerinden biri de bankaların elde ettikleri kar ile yetinmeyip kabul edilebilir bir risk iştahı sınırlarından çıkıp kontrollü bir şekilde davranmamalarıdır.

2008 Küresel finansal mali kriz, sistemik riskin belirleyicisi olarak banka büyüklüğü konusunda bir tartışmayı ortaya çıkarmıştır. Bu tartışmanın ortaya çıkmasına neden olan faktörlerden birincisi, son krizin merkezinde büyük bankaların yer alması, ikincisi, büyük bankaların büyüklüğü son yirmi yılda önemli ölçüde artmış olması, üçüncüsü ise büyük bankalar daha düşük sermaye oranlarına, daha az istikrarlı finansmana ve potansiyel olarak riskli piyasa tabanlı faaliyetlere daha fazla maruz kalma eğiliminde olmalarıdır. (Laeven, Ratnovski, \& Tong, 2016)

$\mathrm{Bu}$ durum ortaya bir dizi ekonomik soruyu ortaya çıkarmaktadır. Birincisi, büyük bankalarda riskin kaynağ tam olarak nedir? Düşük sermaye, istikrarsız finansman, piyasa temelli faaliyetler, kendi başına büyüklük veya sayılan tüm faktörlerin bir kombinasyonu mu? İkincisi, bu potansiyel risk faktörleri bağımsız banka riski üzerindeki etkileriyle sistemik riski yönlendiriyor mu veya sistemik risk üzerinde bunun ötesine geçen bağımsız banka riski üzerinde bir etkisi var mı? (Laeven, Ratnovski, \& Tong, 2016)

Bankacılık sektöründe finansal istikrar açısından büyüklük kriteri finansal sistem içerisinde sağladığı finansal hizmetlerin bir göstergesi olarak yer almaktadır. Bankaların sağladığ 1 finansal hizmetlerin çap1 arttıkça risk alma davranışlarının da farklılaştığı görülmektedir. Bunun yanında, bankaların büyüklüğü, diğer bankalar ile olan ilişki derecesi bankaların hizmet olanakları büyüdükçe daha da önemli hale gelmektedir. Bilanço ve bilanço dışı kalemlerin büyüklüğü ve varlıkların büyüklüğü gibi parametreler, bankaların büyüklüklerinin belirlenmesinde önemli kriterler olarak karşımıza çıkmaktadır. (Navruz, 2019).

Bankacılık sektörü faaliyetlerini yürüttüğü aşamalarda risk alma eğilimi, zarar etme olasılığını yansıttığı için risk alma davranışı kavramı önemini gösteren bir olgu olarak kendini göstermektedir. Zarar olasılığının bankaların finansal yapıları üzerinde etkisi birtakım zorlukları beraberinde getirmekte olup bu tür davranışların bankaların performans beklentilerini, rekabet stratejilerini ve faaliyet nakit akışlarını etkileyebilmektedir.

Banka büyüklüğünün risk alma eğilimi üzerindeki etkileri farklı şekillerde ortaya çıkmaktadır. Aktif ölçeği büyük olan bankalar risk yönetiminde daha etkin ve fonlara ulaşma konusunda küçük ölçekleri bankalara göre daha avantajlı olduklarından dolayı riskli yatırımlara karşı eğilimleri daha yüksek olabilmektedir. Buna karşılık büyük ölçekli bankalar denetim açısından daha göz önünde olduklarından risk alma eğiliminden kaçabilme davranışı sergiliyor olabilmektedirler. (Aklan, Akay, \& Çınar, 2014).

\section{Literatür}

Bankaların risk alma eğilimlerini para politikaları, ekonomiye yönelik beklentiler ve bankaların kendilerine özgü yapılarını oluşturan faktörler belirlemektedir. Bankaların risk alma eğilimi; mevduatın ve kredilerin aktifleri içindeki payı, sendikasyon kredilere ulaşımı, sermaye yapısı, faaliyet oranları ve karlılık oranlarından etkilenmektedir.

Bankaların büyüklüklerinin risk alma davranışı üzerinde etkili olduğu ifade edilmektedir. Bu durum karşısında çeşitli müdahaleler sayesinde büyük finansal kuruluşların batmasina izin verilmemesi olarak ifade edilebilen batmayacak-kadar-büyük olgusu (Too Big to Fail) ortaya çıkabilmektedir

Gropp ve Vesala (2001), 1992-1998 dönemleri arasında Avrupa Birliği bankacılık sektöründe banka risk düzeyi ve banka büyüklüğü arasındaki ilişkileri incelemişlerdir. Çalışma sonucunda, büyük ölçekli bankaların daha fazla risk aldıkları sonucuna dolaylı olarak ulaşmışlardır.

Jimenez vd. (2007) yaptıkları çalışmada bankalar arası piyasadan daha çok borçlanmak zorunda kalan küçük bankaların büyük bankalara göre daha fazla risk alma eğiliminde olduğunu ortaya çıkarmışlardır.

Hakanes ve Schnabel (2011) Basel II Sermaye Anlaşması kapsamında bankaların risk alma davranışı ile banka büyüklüğü arasındaki ilişkiyi ortaya koymak için yaptıkları istatistiki çalışmada banka büyüklüğünün Basel II kapsamında bankalara rekabet avantajı sağladığı, bunun yanında küçük bankaların ise daha yüksek riske girmelerine neden olacağından daha fazla riske maruz kaldıkları sonucuna ulaşmışlardır. Bu rekabet çarpıklıklarının sadece rekabet politikası açısından değil, aynı zamanda bankacılık sektöründe toplam riski artırdığ 1 için finansal istikrar açısından da endişe verici olduğunu ifade etmişlerdir. Bunun yanında burada yer alan temel sorunun bankaların standartlaştırılmış ve IRB (Internal Rating Based) yaklaşımları arasında seçim yapma hakkından kaynaklandığı bu durumun düzenleme ile küçük ve büyük bankaların asimetrik muamelesine yol açmasıdır.

Barrell vd ( 2012), 1993- 2008 dönemleri arasında banka büyüklüğü ve risk alma eğilimleri arasındaki ilişkiyi 713 OECD bankası için GMM tahmini kullanılarak ortaya koymaya çalışmışlardır. Çalışmada Subprime krizinin ardından, kendilerini başarısızlığa uğramayacak kadar büyük' olarak değerlendirebilecek büyük bankaların finansal sisteme getirdiği orantısız riskleri ortaya çıkardığı bu durumunda banka büyüklüğünü ve karmaşıklığını azaltma etkisine sahip radikal politikalara ihtiyaç duyulabileceği önerilerini ifade etmişlerdir. Çalışma sonucunda banka büyüklüğünün zarar olasılığını yansıtan risk alma eğilimi ile gerçekten ilişkili olduğunu ve büyük oranda küçük sermayeye sahip bankaların olumsuz teşviklere karşı daha savunmasız olduğu sonucuna ulaşmışlardır. 
Aklan vd (2014), 2002-2012 dönemleri arasında para politikalarının bankaların risk alma eğilimlerini arasındaki ilişkiyi dinamik panel yaklaşımı ile ortaya koymaya çalışmışlardır. Çalışma sonucunda kısa vadeli faiz oranlarındaki değişim ile bankaların risk alma eğilimleri arasında pozitif yönlü bir ilişkinin varlığını tespit etmişlerdir. Buna ilaveten Türk bankacılık sektöründe faizlere karşı gösterilen reaksiyon banka büyüklüğüne göre değişmekte olduğunu ve özellikle günümüzde olduğu gibi faizlerin olması gereken değerin altında olduğu durumlarda büyük bankaların kredi riskine karşılık risk alma eğilimlerinin azaldığı ifade etmişlerdir.

Bhagat vd (2015), 2002-2012 dönemleri arasında finansal kuruluşlar arasında firma büyüklüğü ile risk alma arasındaki ilişkiyi Z-skoru ile ortaya koymaya çalışmışlardır. Çalışma sonucunda büyüklüğün risk alma önlemleriyle pozitif bir şekilde ilişkili olduğunu, finansal kurumların kaldıraç oranını artırarak aşırı risk almaya giriştiğini, daha iyi kurumsal yönetişimden yararlanan bankaların daha az risk aldıkları ve yatırım bankalarının ticari bankalara kıyasla daha fazla risk aldıkları sonucuna ulaşmışlardır.

Luu (2015), gelişmekte olan Asya Ülkeleri'nde, kurumsal yönetişimin ve düzenlemelerin banka risk alma davranışı üzerindeki etkilerini ortaya koymaya çalışılmıştır. Çalışma sonucunda Kurumsal yönetim mekanizmasının banka tarafından alınan risk düzeyi üzerinde güçlü bir etkiye sahip olduğu, büyük sahibi / sahipleri olan bankalar daha yüksek risk alma ile ilişkiliyken, yönetim kurulu büyüklügünnün banka risk düzeyiyle olumsuz yönde ilişkili olduğu tespit edilmiştir.

Pham (2015), 2006-2015 dönemleri arasında Vietnam'da faaliyet gösteren $30 \mathrm{kamu}$, özel ya da her iki sermayeli ticari bankanın banka büyülüğünün(aktif büyüklüğü) risk alma davranışı (Z-Score) üzerinde etkisi olup olmadığını dengesiz panel verileri üzerinde çeşitli dinamik ekonometri çerçevelerini kullanarak ortaya koyulmaya çalışılmıştır. Çalışma sonucunda bankaların büyüklüğü ile risk alma eğilimi arasında pozitif yönlü, kamu bankalarında herhangi bir ilişki tespit edilemezken, özel sermayeli bankalarda ise negatif bir ilişkinin olduğu sonucuna ulaşmıştır. (Pham, 2016)

Varotto ve Zhao (2018), 2004-2012 dönemleri arasında 83 Amerika, 53 Avrupa bankası arasında firma düzeyinde sistemik riski analiz ettikleri çalışmada sistemik risk göstergelerinin esas olarak firma büyüklüğünden kaynaklandığını ve bunun da "başarısız olamayacak kadar büyük" kurumlar için ağır basan bir endişeye işaret ettiğini ifade etmişlerdir.

Yazıcı vd (2019), 2003-2017 dönemine ait kamu, yabancı ve özel sermayeli bankaların risk alma davranışları ile büyüklükleri arasındaki ilişki Johansen Eşbütünleşme, Vektör Hata Düzeltme Modeli (VECM) ve Wald Testleri kullanılarak ortaya koymaya çalışmıştır. Çalışma sonucunda Kamu ve özel sermayeli bankalarda, bankanın büyüklüğü ile bankanın risk alma davranışı arasında bir ilişkinin olduğu fakat bu ilişkinin kısa dönemde değil uzun dönemde ortaya çıktığını ifade etmişılerdir.

\section{Veri ve Metodoloji}

Çalışmada banka büyüklüğü (ölçeği) bankaların risk alma davranışları üzerindeki etkilerini ortaya koymak için nedensellik testi, Johansen eş bütünleşme ve VEC modeli analiz edilmiştir. Çalışmada 2001-2019 döneminde kamu, yabancı ve özel sermayeli bankaların çeyrek dönem verileri kullanılarak analiz yapılmıştır. Çalışmada bağımlı değişken bankaların takipteki kredilerin ya da sorunlu kredilerin toplam kredilere oranını göstermektedir. Bu oran bankaların risk alma eğilimini belirlemek için kullanılan temel göstergedir (Aklan, Akay, \& Çınar, 2014), (Yazıcı, Göker, \& Oktay, 2019). Çalışmada banka reel aktif büyüklüğünün logaritması (Logaktif) büyüklük değişkeni olarak modelde yer almakta bir başka deyişle Toplam aktiflerin logaritması alınarak belirlenen değişken banka büyüklüğünü ifade etmektedir.

Çalışmada yer alan parametrelerin logaritmik farkları alındığında durağanlık sağladığı takdirde, değişkenler arasında eş bütünleşme olup olmadığı tespit edilmesi gerekmektedir. Parametreler arasında eş-bütünleşme ilişkisinin var olması demek parametreler arasında uzun dönemli bir ilişkinin varlığını ifade etmektedir. İstenilen noktada eşbütünleşme testi için Johansen (1988) yöntemi kullanılmıştır. Kointegrasyon (eşbütünleşme) analizi, zaman serileri alanında kullanılan analiz türü olarak karşımıza çıkmaktadır. Zaman serilerde yer alan temel sorun, serilerin zamanın etkisini bünyelerinde bulundurması ve zamanla artış eğiliminde olmalarından kaynaklanmaktadır. $\mathrm{Bu}$ durum istatistiki çalışmalarda yanıltıcı sonuçlar verebilmektedir. Seriler zamanın etkisinden arındırılabilmek için öncelikle serilerin durağan yap1 göstermesi gerekmektedir. Durağanlığın sağlanmadığı durumlarda parametreler arasında nedensellik ilişkilerin ise vektör hata düzeltme modeli (VECM) ile ortaya konulması gerekmektedir. Granger nedensellik testi ile ortaya konulamayan kısa ve uzun dönemli ilişkiler vektör hata düzeltme modeli ortaya çıkarılabilmekte ve bu sayede nedenselliğin kaynağı hem uzun hem de kısa dönem için ayrı ayrı tespit edilebilmektedir (Yavuz, 2005).

\subsection{Birim Kök Testleri}

Çalışmada, banka büyüklüğü ile risk alma eğilimi arasındaki ilişki, nedensellik testi ,Johansen eş bütünleşme ve VEC modeli analiz edilmiştir İlk aşamada değişkenlerin durağanlık gösterip göstermediğini Augmented Dickey Fuller (ADF). ADF testi kullanılmasındaki amaç model hesaplama öncesinde öncelikle Nedensellik testi modellerinin durağan zaman serilerine ihtiyaç duymaları gerekliliğinden kaynaklanmaktadır. Tablo 1'de ADF Birim Kök Test sonuçları yer almaktadır. 
Tablo 1. ADF ve PP Birim Kök Test Sonuçları

\begin{tabular}{|c|c|c|c|}
\hline & \multicolumn{3}{|c|}{ ADF } \\
\hline \multirow{10}{*}{ 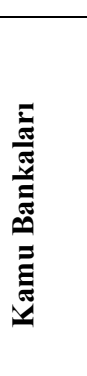 } & \multirow{10}{*}{$\begin{array}{l}\text { (Logaktif)* } \\
\Delta \text { Logaktif*** } \\
\text { Risk*** } \\
\Delta \text { Risk**** }\end{array}$} & Model & t* istatistiği \\
\hline & & Sabit & $7,125 *(0.8765)$ \\
\hline & & & $-5,145^{* *}(0.0015)$ \\
\hline & & & $-6,149 * *(0.5471)$ \\
\hline & & & $-5.456 * * * *(0.0000)$ \\
\hline & & Sabit-Trend & \\
\hline & & & $-9,256 *(0.5641)$ \\
\hline & & & $-5,145^{* *}(0.0012)$ \\
\hline & & & $-6,149 * *(0.1245)$ \\
\hline & & & $-11,145^{* * *}(0.0019)$ \\
\hline \multirow{9}{*}{ 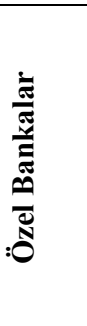 } & \multirow{9}{*}{$\begin{array}{l}\text { (Logaktif)* } \\
\Delta \text { Logaktif** } \\
\text { Risk }^{* * *} \\
\Delta \text { Risk }^{* * * *}\end{array}$} & Sabit & $-11,476 *(0.0053)$ \\
\hline & & & $-9,753 * *(0.0010)$ \\
\hline & & & $-7,128 * *(0.1245)$ \\
\hline & & & $-6.149 * * * *(0.0010)$ \\
\hline & & Sabit-Trend & \\
\hline & & & $-8,256 *(0.1241)$ \\
\hline & & & $-5,749 * *(0.0000)$ \\
\hline & & & $-8,127 * *(0.3275)$ \\
\hline & & & $-13,146 * * *(0.1219)$ \\
\hline \multirow{9}{*}{ 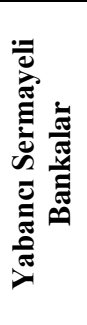 } & \multirow{9}{*}{$\begin{array}{l}\text { (Logaktif)* } \\
\Delta \text { Logaktif*** } \\
\text { Risk*** } \\
\Delta \text { Risk**** }\end{array}$} & Sabit & $-3,143 *(0.5244)$ \\
\hline & & & $-3,749 * *(0.9242)$ \\
\hline & & & $-3,231 * *(0.4176)$ \\
\hline & & & $-5.147 * * * *(0.0014)$ \\
\hline & & Sabit-Trend & \\
\hline & & & $-4,135 *(0.4563)$ \\
\hline & & & $-2,149 * *(0.0015)$ \\
\hline & & & $-4,456^{* *}(0.0005)$ \\
\hline & & & $-1,137 * * *(0.0042)$ \\
\hline
\end{tabular}

Not: $\Delta$ serilerin logaritmik değerlerinin alındığını göstermektedir.

ADF birim kök testi uygulanması sonucunda serinin hiçbir düzeyde durağan olmadığı tespit edilmiş ve bunun üzerine serilerin birinci dereceden farkı alınarak ADF testi uygulanmıştır. Tablo 1'de yer alan sonuçlara göre tüm serilerin birinci derecede durağan olduğu tespit edilmiştir.

\subsection{Eş Bütünleşme Testi}

Serilerin aynı seviyede durağanlaştıkları tespit edildikten sonra Johansen eşbütünleşme testi uygulanabilmektedir. Tablo 2. Johansen Eşbütünleşme Test Sonuçları
Johansen eş bütünleşme testi uygulanmadan önce gecikme sayısının tespiti büyük önem arz etmektedir. AIC, bilgi kriterlerine göre gecikme sayısını Kamu Bankaları için 1, yabancı sermayeli ve özel sermayeli bankalar için ise 2 olarak alınması gerektiği tespit edilmiştir. $\mathrm{Bu}$ aşamadan sonra Johansen Eş-bütünleşme testi yapılabilmektedir. Burada eşbütünleşme için seriler birincil farkları bütün değişkenler için birim kök testi sonuçlarına göre durağan hale getirilmiştir.

Rank

Trace İst.

Kritik Değer (0.05) Max İst.

Kritik Değer (0.05)

\begin{tabular}{|c|c|c|c|c|c|}
\hline 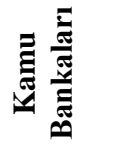 & $\begin{array}{l}\mathrm{r}(\pi)=0 \\
\mathrm{r}(\pi) \leq 1 \\
\mathrm{r}(\pi) \leq 2\end{array}$ & $\begin{array}{l}27.4562 \\
5.6542 \\
0.0045\end{array}$ & $\begin{array}{l}15.1456 \\
12.456 \\
3,47\end{array}$ & $\begin{array}{l}20.1456 \\
5.6961 \\
0.0049\end{array}$ & $\begin{array}{l}12.4571 \\
11.1456 \\
3.47\end{array}$ \\
\hline : & $\begin{array}{l}\mathrm{r}(\pi)=0 \\
\mathrm{r}(\pi) \leq 1 \\
\mathrm{r}(\pi) \leq 2\end{array}$ & $\begin{array}{l}25.145 \\
5.1467 \\
0.0145\end{array}$ & $\begin{array}{l}15.1456 \\
12.456 \\
3,47\end{array}$ & $\begin{array}{l}14.1246 \\
4.9576 \\
0.0041\end{array}$ & $\begin{array}{l}12.4571 \\
11.1456 \\
3.47\end{array}$ \\
\hline 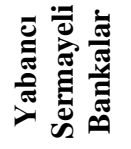 & $\begin{array}{l}\mathrm{r}(\pi)=0 \\
\mathrm{r}(\pi) \leq 1 \\
\mathrm{r}(\pi) \leq 2\end{array}$ & $\begin{array}{l}25.468 \\
5.1685 \\
0.4132\end{array}$ & $\begin{array}{l}15.1456 \\
12.456 \\
3,47\end{array}$ & $\begin{array}{l}14.325 \\
4.9990 \\
0.0051\end{array}$ & $\begin{array}{l}12.4571 \\
11.1456 \\
3.47\end{array}$ \\
\hline
\end{tabular}

Tablo 2'de yer alan istatistiki sonuçlara göre Trace test istatistiğinde birinci hipotez hipotez $(\mathrm{r}=0)$ "Hiç eş bütünleşik vektör yoktur"; şeklinde ikinci hipotez $(r \leq 1)$ "En az bir tane eş bütünleşik vektör vardır” şeklinde 
kurulmaktadır. Aynı şekilde Maksimum test istatistiğinde birinci hipotez hipotez ( $\mathrm{r}=0)$ "Hiç eş bütünleşik vektör yoktur"; şeklinde ikinci hipotez $(\mathrm{r} \leq 1)$ "En az bir tane eş bütünleşik vektör vardır" şeklinde kurulmaktadır. Birinci hipotezinin reddedilmesi En az bir tane eş bütünleşik vektör bulunduğunu; ikinci hipotezinin reddedilmesi En az iki tane eş bütünleşik vektör bulunduğunu; üçüncü $(r \leq 2)$ hipotezinin reddedilmesi ise En az iki tane eş bütünleşik vektör bulunduğunu ifade etmektedir. (Ertuğrul, 2013).

Tablo 2'de yer alan sonuçlara göre \%5 anlamlılık seviyesinde hesaplanan değerlerin tüm bankalar açısından kritik değerlerden büyük olduğu görülmüştür. Bu durumda hem trace hem de max istatistiklerine ait temel hipotez $\mathrm{r}=0$ yani eş bütünleşme yoktur hipotezi reddedilmiştir. Sonuç olarak banka büyüklügü ile risk alma eğilimi arasında uzun dönemde bir ilişkinin varlığı tespit edilmiştir. Eş bütünleşme analizi değişkenler arasında uzun dönemli ilişkinin olduğunu ortaya koymasına rağmen Granger nedenselliğin yönü ile ilgili herhangi bir bilgi verememektedir. Bu etkileşimin ortaya konması vektör hata düzeltme modeli kullanılmıştır

Tablo 3. Vektör Hata Düzeltme Modeline Dayalı Granger Nedensellik Test Sonuçları

Kısa Dönem Nedensellik

Uzun Dönem Nedensellik

\begin{tabular}{cccc}
\hline & \multicolumn{1}{l}{ InRisk } & $\mathrm{C}$ \\
\hline $\begin{array}{c}\text { Kamu } \\
\text { Bankaları }\end{array}$ & InAktif & $0.7564(0.6568)$ & $-0.6572(0.0263)$ \\
\hline $\begin{array}{c}\text { Özel } \\
\text { Bankalar }\end{array}$ & Inaktif & $0.5645(0.7458)$ & $-1.7438(0.0273)$ \\
\hline $\begin{array}{c}\text { Yabancı } \\
\text { Sermayeli } \\
\text { Bankalar }\end{array}$ & Inaktif & $2.4568(0.7319)$ & $-1.0873(0.0314)$ \\
\hline Sat: C, uzin & & \\
\hline
\end{tabular}

Not: C, uzun dönem denge ilişkisinden kaynaklanan hata düzeltme terimini, parantez içindeki değerler olasılık değerlerini ifade etmektedir.

Tablo 3'te yer alan Granger nedensellik testi sonucuna göre her üç banka için hata düzeltme terimi $\mathrm{C}$ negatif değerler alması ve anlamlılık seviyelerinin \%5'ten küçük olması kısa dönemde değişkenler arasında nedensellik ilişkisinin olmadığını, uzun dönemli bir nedensellik olduğunu göstermektedir. İstatistiki sonuçlara göre tüm bankalar açısından, bankaların büyüklüğü ile risk alma eğilimi arasında bir ilişkinin varlığ tespit edilmiştir.

Değişkenlerin istatistiki açıdan anlamlı ve negatif değerler alması büyük bankaların düşük düzeyde sorunlu kredilere sahip olduğu, bir başka ifadeyle daha sağlıklı bir portföy yapısına sahip olduklarını ifade etmektedir. $\mathrm{Bu}$ durum büyük bankaların küçük bankalar göre risk alma eğilimlerinin daha çok olduğunu gösterebilmektedir. Literatürde yapılan birçok çalışmada bankaların risk alma davranışını ortaya koymada birçok değişken önemli olmasına karşın Burada önemli olan nokta bankaların karakteristik özelliklerinden biri olan banka büyüklüğünün önemi ve banka büyüklüğünün risk alma eğilimi açısından en önemli değişken olduğu söylenebilir.

\subsection{Tanısal (Diagnostic) Test Sonuçları}

Tablo 4'te modele ait tanısal test sonuçlarına bakıldığında hesaplanan $\mathrm{F}$ istatistik değerinin tablo üst kritik değerinden büyük olması değişkenler arasında eşbütünleşme ilişkisinin olduğunu göstermektedir. Bunun yanında Modele ait tanısal test sonuçlarına bakıldığında Breusch-Godfrey LM Testi otokorelasyonun olmadığını, Breusch-Pagan-Godfrey modelde değişen varyans sorununun olmadığını, Jaque Bera değeri modelde normal dağılım sorunu olmadığını, Ramsey Reset testi modelde model kurma hatasının olmadığını göstermektedir.

Tablo 4. Tanısal (Diagnostic) Test Sonuçları

\begin{tabular}{ll} 
Test & F-İstatistik \\
\hline & \\
Breusch-Goldfrey LM test İstatistik değeri & $1.06(0.4358)$ \\
Jarque Bera İstatistik değeri & $3.02(0.5687)$ \\
Ransey Reset Test İstatistik değeri & $0.43(0.6378)$ \\
White Heteroskedasticity Testi & $1.78(0.6319)$
\end{tabular}

\section{Sonuç}

Dünya da yaşanan finansal krizlere bakıldığında ekonomide yapılan regülasyonlar ve liberalizyonlar hala eksiklikleri bünyesinde bulundurduğu için bankaların karşılaştıkları risklerin belirlenmesi ve tespiti büyük önem arz etmektedir. Risk yönetimi ile ilgili yapılan literatür çalışmalarının çoğunda, risk yönetim uygulamalarının bankaların değerini arttırdığ1 görülmektedir. 1950'den günümüze kadar risk yönetiminin bankaların değeri üzerindeki etkisinin gözlemlenmesiyle birlikte bankalar risk yönetimine daha fazla önem vermeye başlamışlardır. Bankalar bünyelerine entegre edeceği risk yönetimini oluştururken sermaye yapılarına göre maruz kaldıkları risklerin sağlıklı ve etkin bir şekilde tespiti ve ölçümü gerekmektedir. 
Bankacılık sektörüne yönelik yapılan bu çalışmada sermaye yapısı açısından aktif büyüklüğünün Türk Bankacılık sektöründe faaliyet gösteren bankaların risk alma davranışları üzerindeki etkisini nedensellik testi, Johansen eş bütünleşme ve VEC modeli analiz edilmiştir. Çalışmada 2001-2019 döneminde kamu, yabancı ve özel sermayeli bankaların çeyrek dönem verileri kullanılarak analiz yapılmıştır. Tasarrufun sağlanma biçimi açısından farklı ortaklık yapısına ait bankaların varlığı gözetilerek üç farklı banka yapısı incelenmeye çalışılmıştır. Yapılan birçok çalışmada banka karakteristikleri açısından anlamlı bulunan en önemli değişkenin banka büyüklüğü olduğu ortaya çıkmıştır. Özellikle günümüzde faiz oranlarında yaşanan volatilite hareketleri açısından ele alındığında Türk bankacılık sektöründe faizlere karşı gösterilen reaksiyon banka büyüklüğüne göre değişmektedir. Çalışmada ortaya çıkan bulgulara göre sahiplik yapısı fark etmeksizin tüm bankalar açısından, bankaların büyüklüğü ile risk alma eğilimi arasında bir ilişkinin varlığı tespit edilmiştir. Ortaya çıkan bulgu Türkiye'de bankacılık sektöründe sahiplik yapısı kamu, özel ya da yabancı sermaye fark etmeksizin büyük bankaların risk alma eğilimlerinin de fazla olduğu yönündedir bu durum da batamayacak kadar büyük olgusunun Türk bankacılık sektörü için geçerliliğini ortaya koymaktadir.

\section{Kaynakça}

Aklan, A., Akay, H. K., \& Çınar, M. (2014). Türkiye'de Para Politikalarının Bankaların Risk Yüklenimleri Üzerindeki Etkileri, . Uluslararası Yönetim İktisat ve Işletme Dergisi,, 10(21).
Ertuğrul, H. M. (2013). Türkiye'de Enerji Tüketimi GSYH İlişkisi: Dinamik Bir Analiz. Sosyal Ekonomik Araştırmalar Dergisi,, 25, 249-266.

ITO, T. (2011). Reform of Financial Supervisory and Regulatory Regimes: What has Been Achieved and What is Still Missing. International Economic Journal, 25(4), 553-569.

Laeven, L., Ratnovski, L., \& Tong, H. (2016). Bank size, capital, and systemic risk: Some international evidence. Journal of Banking \& Finance, 69(1), 25-34.

Navruz, B. (2019). Bankacllikta Sistemik Risk Sorunu ve Pigovian Çözüm Yaklaşımı: Türk Bankacılık Sektörü Açısından Bir Değerlendirme. (G. M. A.Ş, Dü.) İstanbul: Türkiye Bankalar Birliği,.

Pham, M. (2016). Bank Size, Ownership and Risk-Taking Behavior: An Empirical Study of Vietnamese Commercial Banks . SSRN Electronic Journal.

Varatto, S., \& Zhao, L. (2018). Systemic Risk and Bank Size. Journal of International Money and Finance, 82, 45-70.

Yavuz, N. Ç. (2005). Türkiye'de İhracat ve İktisadi Büyüme Arasında Nedensellik Analizi. Istanbul Üniversitesi Sosyal Siyaset Konferansları. 49, s. 964. İstanbul Üniversitesi.

Yazıc1, E., Göker, İ. K., \& Oktay, M. .. (2019). Türk Bankacılık Sektöründe Büyüklüğün Risk Alma Davranışı Üzerindeki Etkisi. Muhasebe ve Finans Incelemeleri Dergisi, 2(2), 149-154. 